\title{
Efficacy of Sensory Re-Education Paradigm on Functional Outcomes in Patients with Carpal Tunnel Syndrome
}

\author{
FATIMAH I. ABDUL-SHAFY, M.Sc.*; YOUSSEF M. AL-BALAWY, Ph.D.*; HODA M. ZAKARIA, Ph.D.* and \\ EBTESAM M. FAHMY, M.D.**
}

The Department of Physical Therapy for Neuromuscular Disorders and its Surgery, Faculty of Physical Therapy* and The Department of Neurology, Faculty of Medicine**, Cairo University, Egypt

\begin{abstract}
Background: Carpal Tunnel Syndrome (CTS) is the most common entrapment neuropathy due to compression of the median nerve as it travels through the wrist at the carpal tunnel. The function of the hand can be severely affected by the sole loss of sensibility of the hand even though motor function is normal. Until now there is no optimal physical therapy protocol for making patients with CTS satisfied with the functional outcomes therefore most of patients are refuge to surgical interference.
\end{abstract}

Aim of Study: To investigate the efficacy of sensory reeducation paradigm on pain intensity, symptom severity, and functional outcomes in carpal tunnel syndrome patients.

Subjects and Methods: Thirty patients suffering from mild to moderate carpal tunnel syndrome were enrolled. They were randomly assigned into two equal groups. The study group (A): Received sensory re-education paradigm in addition to a selected physical therapy program. The control group (B): Received the same selected physical therapy program only. Pain intensity level was assessed by the visual analogue scale (VAS), symptom severity and functional outcomes were assessed by Boston Carpal Tunnel Syndrome Questionnaire (BCTQ). The assessment was done before and after twelve treatment sessions.

Results: There was a statistically significant improvement in pain intensity, and symptom severity in both groups post treatment. There was a statistically significant improvement in functional status score post treatment only in group (A) $(p<0.05)$. A significant difference was recorded between both groupsin favor of the study group in functional status scorepost treatment $(p<0.05)$

Conclusion: Adding Sensory re-education paradigm to traditional physical therapy is a beneficial rehabilitation program in improving the functional outcomes in patients with CTS.

Key Words: Carpal tunnel syndrome - Sensory re-education - Sensory relearning - Functional outcomes.

Correspondence to: Dr. Fatimah I. Abdul-Shafy, E-Mail: fatemahibrahim@cu.edu.eg

\section{Introduction}

CARPAL Tunnel Syndrome (CTS), Carpal tunnel syndrome is the commonest of the entrapment neuropathies in the upper limb with middle aged persons being at higher risk. Females are more likely to develop CTS than males with a female to male ratio of $3: 1$. [1].

Classic CTS symptoms include numbness and tingling in the median nerve distribution of the hand, and, in more severe cases, loss of strength of muscles innervated distally by the median nerve. Median nerve pathology impacts all nerve functions distal to the site of lesion, with some possible pain being felt proximally to the shoulder [2].

In early CTS, sensory latencies are more likely to be prolonged than motor latencies; intermediate CTS included constant sensory deficits and possible

\footnotetext{
Abbreviations:

BCTQ : Boston Carpal Tunnel Questionnaire.

BCTSQ : Boston Carpal Tunnel Syndrome Questionnaire.

BM : Body Mass Index.

CTR : Carpal Tunnel Release.

CTS : Carpal Tunnel Syndrome.

D2 : Second Diagonal.

ECTR : Endoscopically Assisted Carpal Tunnel Release.

EDX : Electro-Diagnostic Study.

MMDL : Median motor distal latency.

MSDL : Median sensory distal latency.

MSV : Median Sensory Velocity.

NCS : Nerve Conduction Study.

OCTR : Open Carpal Tunnel Release.

PNF : Proprioceptive neuromuscular facilitation.

RCT : Randomized control trial.

SR : Sensory Re-Education.

TCL : Transverse Carpal Ligament.

UE : Upper extremity.

VAS : Visual Analogue Scale.
} 
motor impairment, and advanced CTS included severe loss of sensory and motor function, as well as thenar muscle atrophy [2].

Treatment of CTS includes Physical therapy as splinting, mobilization of carpal bone and median nerve mobilization [3]. Surgical decompression, an option offered to the patient in case of failure of conservative management. Surgery is performed via an open carpal tunnel release (OCTR) or endoscopically assisted carpal tunnel release (ECTR). Surgical decompression involves transaction of the transverse carpal ligament (TCL) to relieve pressure on the median nerve [4].

The transverse carpal ligament may play a role in proprioception of the wrist in addition to its function as a mechanical wrist stabilizer [5].

Most physiotherapists focus on motor improvements rather than the sensibility improvements though the sensory system may have an upper hand in improving the motor function [6,7]. Until now there is no optimal physical therapy protocol for making patients with CTS satisfied with the functional outcomes therefore most of patients are refuge to surgical interference $[8,9]$.

Because of the limited evidence available and the variation between the interventions studied, no specific sensory re-education intervention can be recommended yet. On theoretical grounds, the methods of treatment described by Dellon and Wynn-Parry may be most promising torestore functional sensibility [10].

Therefore; sensory re-education paradigm should be assessed in randomized trials with blinded assessment of functional outcomes to evaluate its effectiveness in patients with CTS.

\section{Subjects and Methods}

\section{Subjects:}

The study was a randomized controlled trial (RCT) carried on thirty female patients with CTS. The patients were recruited from the outpatient clinic at Faculty of Physical Therapy and the Clinical Neurophysiology Unit of Cairo University Hospitals, in the period between March 2019 to May 2019. Patients were diagnosed and referred by a neurologist or a neurosurgeon as CTS based on the clinical diagnostic criteria of the American Academy of Neurology, [11]. The study was approved by ethical committee of faculty of physical therapy, Cairo University (P.T.REC/012/002260).
The patients signed written informed consents before participation after comprehensive explanation of the aim and procedures of the study to ensure complete satisfaction.

Patients were randomly assigned by sealed paper envelopes into two equal groups: The experimental group $(n=15)$ received twelve sessions of sensory re-education paradigm andthe control group $(n=15)$ received twelve sessions of the same standard physical therapy program only.

Inclusion criteria were: Thirty female patients reported pain, hyperesthesia, and/or paresthesia at the course of median nerve distribution [2,12], were diagnosed as CTS based on the clinical diagnostic criteria of the American Academy of Neurology [12], their age ranged from 20 to 50 years old, body mass index $\leq 25\left(\mathrm{~kg} / \mathrm{m}^{2}\right)$, fractionated sensory nerve conduction velocity for the median nerve across the wrist of $40 \mathrm{~m} / \mathrm{s}$ or less [13], and with sensory distal latency more than $3.6 \mathrm{~ms}$ and less than $4 \mathrm{~ms}$ [14].

Exclusion criteria were: CTS due to Systemic disease (i.e. thyroid disease, diabetes mellitusrheumatoid arthritis,), obese or pregnant women, patients who have wasting of the thenar muscles, previous surgery for CTS, complete conduction block on EDX or previous regular exposure to hand-held vibrating tools, presence of cervical radiculopathy, presence of other concomitant neurological disease (i.e. peripheral neuropathy), History of wrist fracture, surgery or carpal tunnel injection in the last 2 weeks before study, and history of wrist surgery, fracture or injection at carpal tunnel in the last 2 weeks before study.

Evaluation procedures:

All patients were evaluated pre- and posttreatment using:

Visual analogue scale (VAS):

Sensation of pain at wrest was evaluated by the patients under supervision of the same examiner using a visual analogue scale (VAS) [15]. Patients were asked to mark a $100 \mathrm{~mm}$ line to indicate pain intensity. The score was measured from the zero anchored to the patient's mark [16].

Boston Carpal Tunnel Syndrome Questionnaire $(B C T Q)$ :

It was used to measure the severity of symptoms of CTS and to assess the functional status of the affected hand. 


\section{Treatment procedures:}

Study group A: The patients were treated by a twelve sessions of sensory re-education paradigm forfifty minutes per session, day after day, for four weeks. The patients also received traditional therapeutic exercises (tendon and median nerve gliding exercises \& graduated active and resisted strengthening exercises) for ten minutes per session, three sessions per week for four weeks. So the total session time was an hour as follows:

\section{The sensory reeducation paradigm:}

Step 1: Splinting as a constant maintained touch for fifteen minutes:

The patient's extremity was rested on a stable surface and the splint was donned well for fifteen minutes with holding the wrist in the neutral position as this position has less pressure and, therefore, greater potential to provide relief from symptoms [17].

Step 2: Topical anesthesia for pain reduction using $8 \%$ lidocaine spray for fifteen minutes as following:

The patient's extremity was rested on a stable surface. Topical anesthesia using $8 \%$ lidocaine spray was applied to the affected skin for fifteen minutes.

Step 3: Massage; graduating from the softest to rougher one with same speed and pressure for fifteen minutes as following:

The patient's extremity was rested on a stable surface and then apply mini-massage, as tolerated, over sensitive areas for five minutes with same speed, pressure and direction then the light pressure to rub these materials from cotton, velvet, terry cloth, polyester to wool over sensitive areas (each material for two minutes)was used $[\mathbf{1 8 , 1 9 ]}$.

Step 4: Proprioceptive neuromuscular facilitation (PNF) technique using the second upper extremity (UE) diagonal (D2); pattern comprises shoulder Extension/Adduction/Internal Rotation. for five minutes as the following steps:

- The patient was asked to sit on chair with her back well supported, with relaxed, flexed, abducted, and externally rotated shoulder, with extended elbow and opened hand.

- The therapist stood slightly beside the patient putting distal hand on patient's palm and proximal hand on the postero-medial aspect of patient's arm to apply slight resistance,
- The patient was asked to squeeze her hand and move her arm against resistance to the opposite pattern.

- The therapist took forward stride step while the patient moving her arm.

- That pattern was repeated for five minutes.

The second upper extremity (UE) diagonal (D2) pattern comprises shoulder Extension/Adduction/ Internal Rotation. The arm to be finally extended across the body with the elbow crossing the midline, forearm pronated, wrist and fingers flexed, and wrist ulnarly deviated. The clinician asked the patient to "pull your wrist and arm to your opposite lap" [20].

\section{The physical therapy program:}

Tendon gliding exercises:

Tendon gliding exercises provide active flexibility for the flexor tendons. The exercises were performed with the patient sitting on a chair with her back supported. The shoulders and neck were in a neutral position, her forearm supinated and flexed ninety degrees.

There were five steps in which the patient performs tendon gliding exercises:

- The 1 st step (straight): The patient was asked to hold her hand midway between flexion and extension with her thumb abducted.

- The 2nd step (hook): The patient was asked to perform flexion of both proximal and distal interphalangeal joints, while extension of the metacarpophalangeal joints of the medial four fingers was maintained and the thumb was adducted.

- The $3^{\text {rd }}$ (fist): The patient was asked to flex her thumb and fingers.

- The $4^{\text {th }}$ step (table top): The patient was asked to perform extension of both proximal and distal interphalangeal joints, while she flex her metacarpophalangeal joints of the medial four fingers and the thumb was kept adducted.

- The $5^{\text {th }}$ step (straight fist): The patient was asked to flex her both metacarpophalangeal joints and proximal interphalangeal joints while extending the distal interphalangeal joints of the medial four fingers and the thumb was adducted.

Median nerve gliding exercises:

The median nerve was mobilized through six steps of gliding exercises from extended arm:

- The $1^{\text {st }}$ step, the patient was asked to hold her wrist in a neutral position, and flex all fingers and thumb. 
- The 2nd step, the patient was asked to hold her wrist in a neutral position with the thumb and fingers extension.

- The $3^{\text {rd }}$ step; the patient was asked to extend her wrist and fingers with the thumb in a neutral position.

- The $4^{\text {th }}$ step; the patient was asked to extend her wrist, fingers and thumb.

- The $5^{\text {th }}$ step, the patient was asked to supinate her forearm with maintaining fingers and thumb in extension.

- The $6^{\text {th }}$ step: The therapist applied a gentle stretch to the patient's thumb.

During tendon and median nerve gliding exercises, the patient maintained each position for seven seconds, so that the total duration of the treatment exercise session was about $5 \mathrm{~min}$ for the affected hand [21].

\section{Strengthening exercises:}

The patient sat on chair with her back supported and her shoulders in the neutral position and was asked to perform the actions of wrist flexion, wrist extension, gripping, opposition, pronation, supination, and finger pinchingagainst resistance.

Each exercise was applied 3 sets each set 10 repetitions, relaxation one minute in between [21].

Control group B: The patients received only traditional therapeutic exercises (tendon and median nerve gliding exercises \& graduated active and resisted strengthening exercises) for an hour per session, three sessions per weekfor four weeks.

\section{Statistical analysis:}

The obtained data were collected and statistically analyzed usingStatistical SPSS Package programfor Windows, version 20.

Descriptive statistics including means and standard deviations were for general characteristics of the patients.

As this is a new treatment approach, no power calculation can be performed.

For probable differences between the groups, the Mann-Whitney test or independent sample $t$ test were used.

The Wilcoxon signed-rank test or paired $t$-test was used to analyze within-group differences. The significant level was set at $p \leq 0.05$.

\section{Results}

I- General characteristics of patients in both groups:

In group (A), the mean values for age, weight, height, and body mass index were $40.47 \pm 10.25$ years, $67.49 \pm 3.90 \mathrm{~kg}, 169.00 \pm 8.70 \mathrm{~cm}$ and 24.17 $\pm 1.63 \mathrm{~kg} / \mathrm{m}^{2}$ respectively. In group (B), the mean values for age, weight, height, and body mass index were $39.80 \pm 11.15$ years, $70.00 \pm 5.69 \mathrm{~kg}, 168.00$ $\pm 7.58 \mathrm{~cm}$ and $25.71 \pm 1.44 \mathrm{~kg} / \mathrm{m}^{2}$ respectively. The statistical analysis by independent $t$-test revealed no significant differences between both groups regarding mean age, weight, height or BMI as shown in Table (1).

\section{II- Neurophysiologic parameters in both groups:}

In group A, the mean MMDL was $3.64 \pm 0.84 \mathrm{~ms}$, mean MSDL was $3.79 \pm 0.18 \mathrm{~ms}$, and mean MSV was $38.07 \pm 2.96 \mathrm{~m} / \mathrm{s}$. In group B, the mean MMDL was $3.78 \pm 0.50 \mathrm{~ms}$, mean MSDL was $3.74 \pm 0.21 \mathrm{~ms}$, and mean MSV was $37.96 \pm 3.66 \mathrm{~m} / \mathrm{s}$. The statistical analysis by independent $t$-test revealed nosignificant difference between both groups regarding mean MMDL $(p=0.353)$, mean MSDL $(p=0.541)$, or mean MSV ( $p=0.926)$ as shown in Table (2).

III- Comparison of the measured clinical parameters pre and post treatment within and between groups:

A- Pain assessment using Visual analogue scale (VAS) scores:

In group A: The pre and post-treatment mean scores of VAS were $(7.00 \pm 2.15,2.60 \pm 1.67$ respectively). There was significant decrease in pain level after treatment $(p=0.000)$. In group B: The pre and post-treatment mean scores of VAS were $(5.13 \pm$ $3.02,2.93 \pm 2.18$ respectively). There was significant decrease in pain intensity after treatment $(p=0.004)$. Comparison between groups revealed that there was no significant difference in pain intensity before or after treatment $(p=0.061,0.64$ respectively), as shown in Table (3).

B- Boston Carpal Tunnel Syndrome Questionnaire (BCTSQ) scores:

1- Symptom Severity:

In group A: The pre and post-treatment mean scores of symptom severity were $(2.91 \pm 0.84$, $1.85 \pm 0.65$ respectively). There wasa significant decrease in mean symptom severity score after treatment $(p=0.000)$. In group B: The pre and posttreatment mean scores of symptom severity were $(2.53 \pm 0.91,1.98 \pm 0.66$ respectively). There was a significant decrease in mean SSS after treatment 
( $p=0.011)$. Comparison between groups revealed no significant differences in mean symptom severity scores before or after treatment $(p=0.24,0.61$ respectively), as shown in Table (4).

\section{2- Functional status:}

In group A: The pre and post-treatment mean scores of functional status were $(2.98 \pm 1.07$, $1.92 \pm 0.94$ respectively). There wasa significant decrease in mean functional status score after treatment ( $p=0.000)$. In group B: The pre and posttreatment mean scores of functional status were $(2.59 \pm 1.29,2.13 \pm 0.99$ respectively). There was no significant difference in mean functional status scores before or after treatment $(p=0.07)$. Comparison between groups revealed that there was a significant difference in mean functional status score after treatment in favor of the study group $(p=0.027)$, as shown in Table (5).

Table (1): Characteristics of patients in Groups (A) and (B).

\begin{tabular}{lllllc}
\hline Items & Group (A) & Group (B) & $t$-value & $p$-value & Significance \\
\hline Age (year) & $40.47 \pm 10.25$ & $39.80 \pm 11.15$ & 0.170 & 0.866 & NS \\
Weight $(\mathrm{kg})$ & $67.49 \pm 3.90$ & $70.00 \pm 5.69$ & 0.330 & 0.743 & NS \\
Height $(\mathrm{cm})$ & $169.00 \pm 8.70$ & $168.00 \pm 7.58$ & 0.388 & 0.701 & NS \\
BMI $\left(\mathrm{kg} / \mathrm{m}^{2}\right)$ & $24.17 \pm 1.63$ & $23.90 \pm 1.44$ & 0.939 & 0.354 & NS \\
\hline
\end{tabular}

SD: Standard deviation.

$p$-value: Probability value.

NS: Non-significant.

BMI: Body Mass Index.

Table (2): Neurophysiologic parameters in groups (A) and (B).

\begin{tabular}{llllr}
\hline Variable & $\begin{array}{c}\text { Group A } \\
\text { Mean } \pm \text { SD }\end{array}$ & $\begin{array}{c}\text { Group B } \\
\text { Mean } \pm \text { SD }\end{array}$ & $t$-value & $p$-value \\
\hline MMDL (ms) & $3.64 \pm 0.84$ & $3.78 \pm 0.50$ & 0.619 & 0.353 \\
MSDL (ms) & $3.79 \pm 0.18$ & $3.74 \pm 0.21$ & -0.944 & 0.541 \\
MSV (m/s) & $38.07 \pm 2.96$ & $37.96 \pm 3.66$ & -0.093 & 0.926 \\
\hline
\end{tabular}

MSDL : Median nerve sensory distal latency.

MMDL: Median Nerve Motor Distal Latency.

MSV: Median Nerve Sensory Velocity.

$p$ : Probability value.

$p>0.05=$ Non-significant $(\mathrm{NS})$.

Table (3): Comparison of mean VAS scores before and after treatment within and between both groups.

\begin{tabular}{lllll}
\hline & \multicolumn{3}{c}{ Mean Visual Analogue Scale Score } \\
\cline { 2 - 4 } Items & $\begin{array}{c}\text { Group A } \\
\text { Mean } \pm \text { SD }\end{array}$ & $\begin{array}{c}\text { Group B } \\
\text { Mean } \pm \text { SD }\end{array}$ & $t$-value & $p$-value \\
\hline Pre-treatment & $7.00 \pm 2.15$ & $5.13 \pm 3.02$ & 1.948 & 0.061 \\
Post-treatment & $2.60 \pm 1.67$ & $2.93 \pm 2.18$ & -0.470 & 0.642 \\
$t$-value & 8.438 & 3.410 & & \\
$p$-value & $0.000^{* *}$ & $0.004^{* *}$ & & \\
\hline
\end{tabular}

$p<0.05^{*}=$ Significant

$p<0.00^{* *}=$ Highly significant

$p>0.05=$ Non significant 
Table (4): Comparison of mean symptom severity scores before and after treatment within and between both groups.

\begin{tabular}{lllll}
\hline & \multicolumn{3}{c}{ Mean Symptom Severity Score } \\
\cline { 2 - 4 } Items & $\begin{array}{c}\text { Group A } \\
\text { Mean } \pm \text { SD }\end{array}$ & $\begin{array}{c}\text { Group B } \\
\text { Mean } \pm \text { SD }\end{array}$ & $t$-value & $p$-value \\
\hline Pre-treatment & $2.91 \pm 0.84$ & $2.53 \pm 0.91$ & 1.187 & 0.245 \\
Post-treatment & $1.85 \pm 0.65$ & $1.98 \pm 0.66$ & -0.510 & 0.614 \\
$t$-value & 4.985 & 2.950 & & \\
$p$-value & $0.000^{* *}$ & $0.011^{*}$ & \\
\hline
\end{tabular}

$p<0.05^{*}=$ Significant.

$p<0.00^{* *}=$ Highly significant.

$p>0.05=$ Non significant.

Table (5): Comparison of mean functional status scores before and after treatment within and between both groups.

\begin{tabular}{lllll}
\hline & \multicolumn{3}{c}{ Mean Functional Status Score } \\
\cline { 2 - 5 } Items & $\begin{array}{c}\text { Group A } \\
\text { Mean } \pm \text { SD }\end{array}$ & $\begin{array}{c}\text { Group B } \\
\text { Mean } \pm \text { SD }\end{array}$ & $t$-value & $p$-value \\
\hline Pre-treatment & $2.98 \pm 1.07$ & $2.59 \pm 1.29$ & 2.335 & 0.441 \\
Post-treatment & $1.92 \pm 0.94$ & $2.13 \pm 0.99$ & -0.782 & $0.027^{*}$ \\
$t$-value & 7.333 & 2.200 & \\
$p$-value & $0.000 * *$ & 0.07 & \\
\hline $\begin{array}{l}p<0.05^{*}=\text { Significant. } \\
p<0.00^{* *}=\text { Highly significant. } \\
p>0.05=\text { Non significant. }\end{array}$ & & & \\
& & & \\
\end{tabular}

\section{Discussion}

Carpal tunnel syndrome (CTS) is the commonest one of the entrapment neuropathies in the upper limb with the middle aged persons being at higher risk [22]. CTS manifest clinically with subjective symptoms such as paresthesia and proprioceptive alterations [23]. As the sensory and motor systems are closely related, it may be important to focus not solely on motor training but also to include sensory training in the rehabilitation of CTS [7].

The results of the current study revealed significant decrease in pain intensity and improvement in symptom severity (measured by BCTSQ) posttreatment in groups (I and II), with no significant difference between both groups. Improvement in group (I) agreed with Goransson et al., 2011, who studied 39 patients experiencing hyperesthesia and found that a de-sensitization program showed significant improvement in pain and decrease in the size of the sensitive skin area and higher performance in daily occupations [23]. Improvement of both groups after treatment might be attributed mainly to the effect of the therapeutic exercise program which included a group of exercises for strengthening, gliding the nerve and gliding the tendon. This comes in agreement with Warran, 2001, who reported that standard physical therapy treatment is effective in treatment of CTS symptoms [21].

Lack of superiority in efficacy of sensory relearning when added to the standard physical therapy program, may be explained in view that the effect of sensory re-learning depends on the 'dose' and duration of the intervention which were too low for learning to take effect in this study. This agreed with Jerosch-Herold et al., 2011 who reported that somatosensory rehabilitation, especially sensory relearning, requires short but frequent practice in tactile discrimination tasks [6]. 
On the contrary, a systematic review by Manoli et al., 2016 reported limited evidence supporting the use of early and late sensory relearning modalities in the treatment of peripheral nerve lesions, also only mixed nerves were included in the analysis [26].

In the current study, there was significant improvement of grip strength (motor function) of the affected hand in both groups post treatment, especially in group I. This finding can be attributed to the therapeutic effect of the standard exercise program (e.g., tendon and median nerve gliding), which agreed with Warran, 2001, who reported that standard physical therapy treatment was effective in treatment of for CTS symptoms [27]. The additional improvement in the group who received sensory re-learning may be attributed to improvement of hand sensibility as there is a direct correlation between motor and sensory conduction velocities of the median nerve and hand grip strength in women as reported by Abdel-Fattah et al., 2014 [28].

Improving sensibility threshold will improve motor function and overall functional outcome of the hand [26].

The limitations of this study were the small sample size and lack of measurement of sensory and motor conduction velocities after treatment and studying their correlation with the measured parameters. Another limitation is the short period of applying this paradigm and total number of treatment sessions. However, to the best of our knowledge, no previous studies investigated early sensory re-education efficacy in CTS, hence our results are preliminary. Further research is needed on how to design effective, applicable, and affordable somatosensory rehabilitation programs. This may require more individually tailored exercises to address specific sensory deficits.

With the limitations of this study, it could be concluded that sensory re-education paradigm is a beneficial therapeutic program in the rehabilitation of patients with CTS. Adding this paradigm to the physical therapy program is beneficial in improving functional outcome of the affected hand especially the sensibility threshold and functional status.

\section{Conclusion:}

In view of the results of this study, it could be concluded that sensory re-education paradigm is superior to the standard physical therapy program in improving sensibility threshold, grip strength, and functional status of the affected hand in patients with CTS. So, it is recommended to consider this usefulsafe therapeutic program in the rehabilitation programsof CTS patientsto improve the functional outcomes of the affected in such patients.

\section{Acknowledgements:}

We would like to thank all the patients who took part in the trial.

\section{Funding:}

This research received no specific grant from any funding agency in the public, commercial, or not-for-profit sectors. Personnel funding was by the authors themselves.

\section{References}

1- WOLNY T., LINEK P. and SAULICZ E.: Assessment of manual dysfunction in occupationally active women with carpal tunnel syndrome. Int. J. Occup. Med. Environ Health, 32 (2): 185-196, 2019.

2- ERICKSON M., LAWRENCE M., JANSEN C.W., COKER D., AMADIO P., CLEARY C., et al.: Hand Pain and Sensory Deficits: Carpal Tunnel Syndrome; Clinical Practice Guidelines Linked to the International Classification of Functioning, Disability and Health From the Academy of Hand and Upper Extremity Physical Therapy and the Academy of Orthopaedic Physical Therapy of the American Physical Therapy Association. Journal of Orthopaedic \& Sports Physical Therapy, 49 (5): 1-85, 2019.

3- FATHY SAKR, ENAS ELSYED, YOUSSEF ELBALAWY and AHMED ELNAGAR: Comparison between neural mobilization and carpal bone mobilization in treating carpal tunnel syndrome Bioscience Research, 16 (3): 2690-2698, 2019.

4- TRUMBLE T.E., DIAO E., ABRAMS R.A. and GILBERT-ANDERSON M.M.: Single-portal endoscopic carpal tunnel release compared with open release: A prospective, randomized trial. J. Bone Joint Surg. Am., 84-A (7): 1107-1115, 2002.

5- MASHOOF A.A., LEVY H.J. and SOIFER T.B.: Neural anatomy of the transverse carpal ligament. Clin. Orthop. Relat. Res., 386: 218-221, 2001.

6- JEROSCH-HEROLD C.: Sensory relearning in peripheral nerve disorders of the hand: A web-based survey and delphi consensus method. J. Hand Ther., 24 (4): 292-99, 2011.

7- KESSNER S.S., BINGEL U. and THOMALLA G.: Somatosensory deficits after stroke: A scoping review. Top Stroke Rehabil, 23: 136-46, 2016.

8- DUNCAN S.F. and KAKINOKI R.: Nonoperative Options for the Management of Carpal Tunnel Syndrome in Carpal Tunnel Syndrome and Related Median Neuropathies. Springer International Publishing AG, 109-124, 2017.

9- MENDES R.M., RONDINONI C., FONSECA M.C., BARBOSA R.I., SALMO C.E., BARBIERI C.H. and MAZZER N.: Cortical and functional responses to an early protocol of sensory re-education of the hand using 
audio-tactile interaction. J. Hand Ther., 23 (92): 45-52, 2018.

10- TANJA O., ANITA B., EE F.N. Sensory re-education after nerve injury of the upper limb: A systematic revie. Clinical Rehabilitation, 21: 483-494, 2007.

11- American Association Electrodiagnostic Medicine AAN. American Academy of Physical Medicine and Rehabilitation. Practice parameter for electrodiagnostic studies in carpal tunnel syndrome: Summary statement. Muscle Nerve, 16: 1390-1, 1993.

12- REMPEL D., BACH J.M., GORDON L. and SO Y.: Effects of forearm pronation/supination on carpal tunnel pressure. J. Hand Surg. Am., 23 (1): 38-42, 1998.

13- MAGNUS F., BIRGITTA R., GERT A., TOMMY S., LARS B. DAHLIN and ANDERS BJÖRKMAN: Vibration thresholds in carpal tunnel syndrome assessed by multiple frequency vibrometry: a case-control study. Flondell et al. Journal of Occupational Medicine and Toxicology, 1234, 2017.

14- BAKHTIARY A.H. and RASHIDY-POUR A.: Ultrasound and laser therapy in the treatment of carpal tunnel syndrome. Aust. J. Physiother., 50 (3): 147-151, 2004.

15- CROISIER J.L., FOIDART-DESSALLE M., TINANT F., CRIELAARD J.M. and FORTHOMME B.: An isokinetic eccentric programme for the management of chronic lateral epicondylar tendinopathy. British Journal of Sports Medicine, 41: 269-75, 2007.

16- JENSEN M.P., KAROLY P. and BRAVER S.: The measurement of clinical pain intensity: A comparison of six methods. Pain, 27: 117-26, 1986.

17- YERXA E.J., BARBER L.M., DIAZ O., BLACK W. and AZEN S.P.: Development of a hand sensitivity test for the hypersensitive hand. Am. J. Occup. Ther., 37: 176$81,1983$.

18- CHU M., CHAN R., LEUNG Y. and FUNG Y.: Desensitization of finger tip injury. Tech. Hand Upper Extrem Surg., 5 (1): 63-70, 2001.

19- TERRY C. and CATHY J.F.: Proprioceptive Neuromuscular Facilitation. IPNFAI, 2010.
20- WARREN H.: Carpal Tunnel Exercises that Work. Dynamic Chiropractic, 19 (14), 2001.

21- KWON B.C., JUNG K.I. and BAEK G.H.: Comparison of sonography and electrodiagnostic testing in the diagnosis of carpal tunnel syndrome. J. Hand Surg. Am., 33 (1): 65-71, 2008

22- ARENY-MICAS R., SILVA-DONOSO R., URTUBIAMANRIQUEZ V., SAAVEDRA-MUNOZ J., HERNANDEZ REYES L. and ALISTE-SILVA M.: Vascular changes in severe carpal tunnel syndrome: A differential diagnosis of vasculitis. Reumatol. Clin., 8 (1): 36-8, 2012.

23- GÖRANSSON I. and CEDERLUND R.: A study of the effect of desensitization on hyperaesthesia in the hand and upper extremity after injury or surgery. Hand Therapy, 16: 12-8, 2011.

24- ROSÉN B., BJORKMAN A. and BOECKSTYNS M.: Differential recovery of touch thresholds and discriminative touch following nerve repair with focus on time dynamics. Hand Ther., 19 (3): 59-63, 2014.

25- ROSÉN B., VIKSTRÖM P., TURNER S., McGROUTHER D.A., SELLES R.W., SCHREUDERS T.A.R., BJÖRKMAN A.: Enhanced early sensory outcome after nerve repair as a result of immediate post-operative relearning: A randomized controlled trial. J. Hand Surg., 40E: 598606, 2015

26- MANOLI T., SCHIEFER J.L., SCHULZ L., FUCHSBERGER T. and SCHALLER H.E.: Influence of immobilization and sensory re-education on the sensory recovery after reconstruction of digital nerves with direct suture or muscle-in-vein conduits. Neural Regen Res., 11 (2): 338-344, 2016.

27- ABDEL-FATTAH M.S., SHARAF M.A., EL-GENDY A.M.: Correlation between Hand Grip Strength and Nerve Conduction Velocity in Diabetic Patients. Jokull Journal, 64: 177-185, 2014.

28- CHALLONER T., POWER D.M., BEALE S. and NIJRAN A.: Pathogenesis, Clinical Evaluation and Non-Surgical Management of Symptomatic Neuromas: A Literature Review. Journal of Musculoskeletal Surgery and Research, 3: $15-21,2020$. 


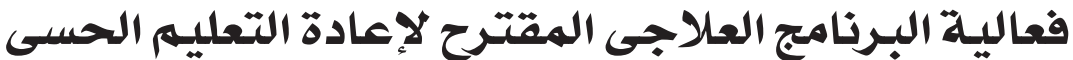

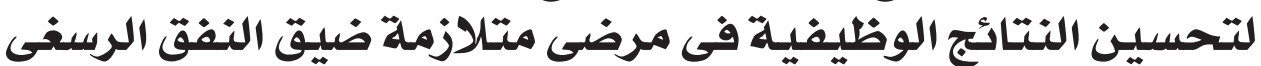

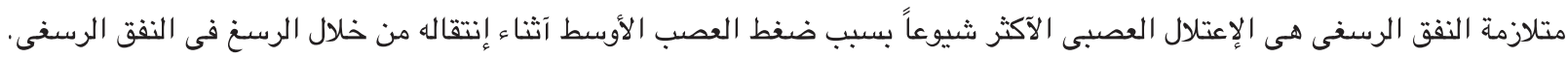

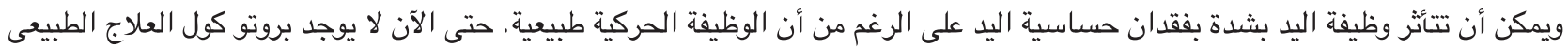

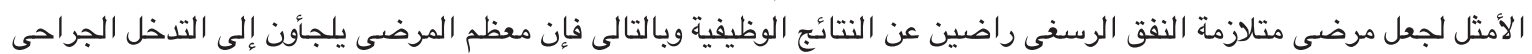

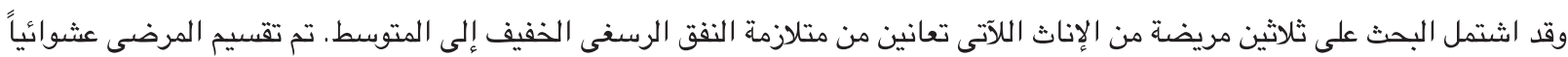

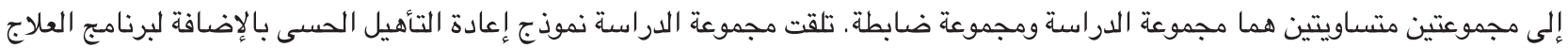

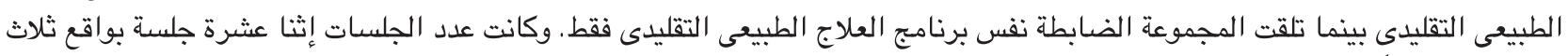

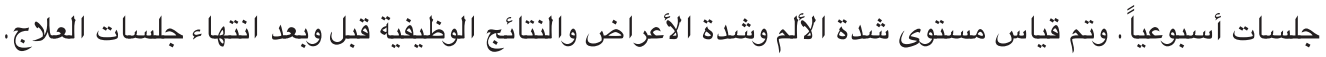

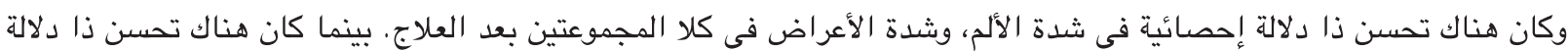

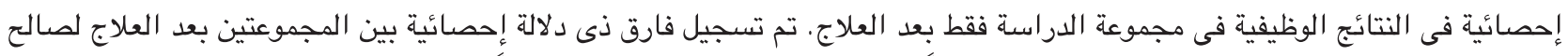

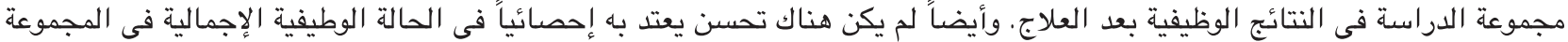
الضابطة.

وقد اشارت النتائج التى تم الحصول عليها إلى أن نموذج إعادة التأهيل الحسى هو برنامج علاجى مفيد فى تحسين النتائج الوظيفية لدى الدي المرضى الذين يعانون من متلازمة النفق الرسفى عند إضافته إلى برنامج العلائه العادئ الطبيعى التقليدى. 